\title{
Supply Constraints and Housing Prices
}

\author{
Saku Aura* $\quad$ Thomas Davidoff ${ }^{\dagger \ddagger}$
}

May 22, 2006

\begin{abstract}
This paper analyzes the effects of land use constraints on housing prices. We provide a new framework for evaluating policy when mobility across regions is allowed but limited. A key result is that loosening regulatory constraints within individual regions would have little effect on prices for plausible parameterizations. For example, we show reasonable conditions under which, even if every building in Manhattan were 100 stories tall, prices would fall by less than 15 percent.

JEL Keywords: Housing Supply and Markets; Regulatory Policies; Land Use Patterns.

*University of Missouri and CESifo, auras@missouri.edu, Phone (573) 882-6073, Fax (573) 882-2697

${ }^{\dagger}$ Haas School of Business, UC Berkeley, davidoff@haas.berkeley.edu, Phone (510) 643-1425, Fax (510)

${ }^{\ddagger}$ We thank Barry Dinerstein of the New York Department of City Planning; Richard Furman; Robert Johnson of Bowman, Barrett \& Associates; and Dwight Jaffee, Peter Mueser, John Quigley, Jacob Sagi, and Johan Walden for helpful suggestions.
\end{abstract} 643-7357 
Regulatory supply constraints are sometimes blamed for high housing prices in the coastal United States. ${ }^{1}$ This paper analyzes the effects of land use constraints in a world in which people are mobile, but preferences over different locations are heterogeneous. A key result of this paper is that loosening density restrictions within individual regions would have little effect on prices for plausible parameterizations. For example, we show reasonable conditions under which, even if every building in Manhattan were 100 stories tall, prices would fall by less than 15 percent. This calculation does not take into account the potential amenity losses and general equilibrium wage changes associated with such extreme population growth. Under the same conditions, in metropolitan New York, halving land prices would require multiplying developpable land supply in existing locations by approximately 15 times.

It is difficult to assess the role of land use constraints empirically because we do not observe the same city at the same time with and without these regulations. ${ }^{2}$ A believable theoretical model of regulations' effects on prices can thus help inform policy debates.

Classical urban economic theory provides two contradictory models to assess impacts, and both rely on unrealistic assumptions. If cities have immobile populations, then land use constraints lower the welfare of the regulated city and may have large price effects if demand for space is inelastic. If there is unfettered mobility across regions, then land use constraints in any individual city have equal welfare effects across all cities and can only raise prices in the regulated city relative to other cities through increased amenity.

This paper considers the effects of land use constraints in a more realistic world in which mobility is free, but consumers balance housing cost against wage differentials or taste for living in one city or another. This mobility scenario is similar to that described by Gyourko et al. [5]. The effects of supply constraints on prices depend on the extent of heterogeneity in willingness to pay for space in the regulated city. With very diverse valuations, we approach

\footnotetext{
${ }^{1}$ See, e.g. Glaeser et al. [4, 3, 2].

${ }^{2}$ Glaeser et al. [2] argue that apartment prices in Manhattan would fall to currently observed (regulated) marginal cost if height restrictions were lifted. This assumes marginal cost is independent of building height. If marginal cost is increasing in building height the resulting equilibrium price would be greater.
} 
the closed city model with fixed population. When tastes are almost homogeneous, we approach the open city model. This approach allows us to extend the work of Arnott and MacKinnon [1], who find small welfare effects of supply constraints in a single closed city. ${ }^{3}$

We assume that the consumer price of a square foot of structure is exogenously given, but land is in limited supply and has an endogenous price. We ask what effect a small increase in the supply of land has on the price of land, ignoring amenity or wage consequences. A direct application of this analysis would be to ask what effect removal of land for critical habitat protection has on land prices (assuming the habitat has no amenity value).

Our model applies equally well to a city where all land is covered by a constrained number of stories of apartments. In that case, land prices become irrelevant to consumers of apartments, conditional on the price per square foot of apartment space, and what we call a unit of "land" can be interpreted as a square foot of apartment space.

The model does not precisely describe height restrictions or minimum lot size requirements in a world in which some people would prefer to live in apartments and others prefer to live in detached homes. We suspect that our results are instructive in those widely applicable cases, but leave more nuanced analysis to future work. We ignore the amenity and wage effects of additional supply and abstract away from within-market heterogeneity of land quality. These abstractions can be justified by noting that the primary argument against supply constraints is that they reduce the supply of housing, thereby raising prices, not that they cause wages or amenities to be different from what they would otherwise be, nor that they distort substitution between land and structures on the land that is available. The sign of wage and amenity effects of supply constraints are ambiguous and depend on the nature of externalities, congestion costs, and the shape of production functions.

\footnotetext{
${ }^{3}$ Arnott and MacKinnon [1] conclude by stating: "It would also be of interest to consider the effect of the openness of the city on the cost of height restrictions. Cases intermediate between the completely open and completely closed city can be dealt with by introducing an elasticity of population with respect to utility." A reduced form elasticity is used in a different context by Wheaton [8]. Our approach provides a microfoundation for population elasticities with respect to prices or incomes.
} 
We consider a static world, meant to represent a long-run equilibrium. We assume for simplicity that profits from land development are distributed to an absentee landlord. We justify this simplification on the grounds that the effect of residents' wealth at the time of zoning on a long-run equilibrium is plausibly small, as do Arnott and MacKinnon [1].

In our model, a continuum of $N$ consumers in a nation may live in any of a number of locations. In one of these locations, an island, there are only $L$ units of land. Because the entire island is assumed to be occupied in equilibrium, there is an endogenous price per unit, which we denote $q$. The island is meant to approximate a region where the quantity of desirable land is limited by transportation costs and perhaps regulation.

Consumer preferences give rise to the price per acre of land $\theta_{i}$ at which they are indifferent between living on the island and living at their next preferred location. We denote land price and wealth for individual $i$ at the next preferred location $o$ by $q_{o i}$ and $y_{o i}$. We assume that the island is sufficiently small relative to other locations (or that other locations have sufficiently elastic land supply) that migration between the island and other locations has negligible effects on the outside prices.

For our purpose, to find the price effect of supply constraints on the island, we only need to know how the willingness to pay per acre of land $\theta_{i}$ is distributed in the national population. To determine welfare effects, one would need to know where $\theta_{i}$ comes from. One source of this distribution would be a distribution of indirect utility functions. For example, $\theta_{i}$ could be defined for an individual $i$ with wealth $y_{i}$ on the island by

$$
v\left(\theta_{i}, 1, y_{i}, \text { live on island }\right)=v\left(q_{o i}, 1, y_{o i}, \text { live in next preferred location }\right)
$$

Specification (1) assumes that taste for living on the island is not associated with demand for land relative to all other goods for island residents. All other goods, including structures in the majority of markets where land consumption matters, are subsumed into a numeraire (hence the " 1 " in the indirect utility function). Land demand for individual $i$ is assumed not to depend on $\theta_{i}$ only for notational convenience.

For all wealth levels, the minimum value of $\theta$ that lives on the island when land costs 
$q$ per acre is $q$, since indirect utility is decreasing in consumer prices. We thus have the following land clearing condition:

$$
N \int_{0}^{\infty} \int_{q}^{\infty} l(q, 1, y) f(y, \theta) d \theta d y-L=0 .
$$

$l(q, 1, y)$ represents marshallian demand for island land. We drop the price arguments from here forward. The bivariate probability density function $f(y, \theta)$ is the density of consumers with wealth $y$ if on the island and indifferent between the island and their next preferred location if the island's price is $\theta$.

We are interested in the change in prices induced by a change in land supply. Differentiating equation (2), we find:

$$
\frac{d q}{d L}=-\left(N\left(\int_{0}^{\infty}-l(y) f(y, q) d y+\int_{0}^{\infty} \int_{q}^{\infty} \frac{\partial l(y)}{\partial q} f(y, \theta) d \theta d y\right)\right)^{-1}
$$

Rearranging equation (3) and defining $\eta_{l q}(y)$ as the elasticity of land demand with respect to price for consumers of wealth $y, \frac{\partial l}{\partial q} \frac{q}{l}$ :

$$
\frac{d q}{d L}=\left(N \int_{0}^{\infty} \frac{l(y)}{q}\left(-q f(q, y)+\int_{q}^{\infty} \eta_{l q}(y) f(\theta, y) d \theta\right) d y\right)^{-1}
$$

Multiplying both sides of equation (4) by $\frac{L}{q}$, we find that the elasticity of land price with respect to supply is:

$$
\begin{aligned}
\eta_{q L} & =\left(N \int_{0}^{\infty} \frac{l(y)}{L}\left(-q f(q, y)+\int_{q}^{\infty} \eta_{l q}(y) f(\theta, y) d \theta\right) d y\right)^{-1} \\
& =\left(-\frac{E(l(q) \mid \theta=q)}{E(l(q) \mid \theta \geq q)} \frac{q f(q)}{1-F(q)}+\bar{\eta}_{l q}\right)^{-1}
\end{aligned}
$$

The inverse of the elasticity is composed of two terms. The first term is a product of two parts. The first part is the ratio of average land demand of marginal entrants to the average land demand of people living on the island. We assume in the following analysis that this ratio is equal to one. ${ }^{4}$ The second part of the first term is the marginal hazard ratio of

\footnotetext{
${ }^{4}$ New entrants' lower willingness to pay might signal lower incomes and hence lower land demand, but could also signal greater land demand holding income constant. This mirrors the ambiguity over whether high or low income residents will live closer to the center of a monocentric city.
} 
living in the island evaluated at $q$ multiplied by $q \cdot{ }^{5}$ The second term $\bar{\eta}_{l q}$ is the elasticity of demand for land of people already living on the island that is weighted by their respective land consumption. We note that $\eta_{q L}$ is negative unless land is a Giffen good.

We can bound the magnitude of $\eta_{q L}$ by noting that Gyourko and Voith [6] summarize empirical estimates for the population average elasticity of land demand with respect to price, $\bar{\eta}_{l q}$, ranging from -.5 to -1.0. Taking the highest value of -.5, we find that the maximum absolute value of elasticity of land price with respect to quantity is 2 . It is unrealistic to think that no one would move in or out of coastal cities if prices change, however, so elasticities must be larger than -2 .

Table 1 summarizes the elasticity of land price with respect to quantity that arises under different distributions of $\theta$ in the population. We consider four distributions: the uniform, the Pareto, the normal and the lognormal. We offer no opinion on which distribution is the most reasonable, except to note that substitution among land, choice of city, and other goods implies that this distribution need not look like the income distribution. We recognize that identifying distributional parameters empirically would be quite challenging. Under the normal and in some cases uniform distributions, there are some negative valuations; our results are unchanged if negative values are replaced with valuations of zero (or any valuation less than $q \cdot)^{6}$

For each of these four distributions, we can calculate the elasticity of interest, $\eta_{q L}$ by specifying: (1) the fraction of national population that lives in a region and (2) the median valuation $\theta$ in the population as a fraction of the price $q$, and by (3) normalizing prices relative to $q=1$. These three specifications are sufficient to identify $f(q)$ and $F(q)$ for any

\footnotetext{
${ }^{5}$ In the expression for the marginal hazard ratio $f(q) /(1-F(q))$, the density $f(q)$ and cumulative distribution function $F(q)$ corresponds to the marginal distribution of $\theta$ that has been derived from the joint distribution of $\theta$ and $y$ integrated over all values of $y$.

${ }^{6}$ Analyzing willingness to live in a metropolitan area as a function of price per unit of land (or floor space) is only meaningful when the population for housing market equilibrium is limited to those who would be willing to move to a metropolitan area if housing were free. Negative threshold price per unit of land for moving into metropolitan area is not consistent with standard consumer choice assumptions.
} 
distribution defined by just two parameters. This is because we know $q$ at two points in the distribution: the 50th percentile and the percentile determined by the region's share of national population. The only controversial specification is choice of the median willingness to pay per acre in the population, and we vary that parameter widely in the simulations. The demand elasticity $\bar{\eta}_{l q}$ and the probability density $f(q)$ should be interpreted as a land-share weighted averages across all incomes, following the discussion above.

We consider valuations of 10, 30, and 60 percent of current price as population medians. That is, we assume that the median American would move to the market in question if prices were 90,70 , or 40 percent lower than the current price. In evaluating the realism of these medians, note willingness to pay should be considerably larger in the long run we consider than in the short run. The lower the population median, the greater the magnitude of $\eta_{q L}$. This is because as the median falls relative to current price, the density of the population that is indifferent between living in the city or not living in the city falls, since this value is moving into the right tail of the distribution and because the variance of the distribution rises, leaving all densities $f(x)$ smaller. When population in the city is large enough, low population median implies infinite expectation for the corresponding Pareto distribution. ${ }^{7}$

In Table 1, we consider the effect of price changes in islands with varying shares of national population and mention real world areas with similar populations. For the cases of Manhattan and Hanover, New Hampshire, we recognize that the assumption that the prices of nearby areas do not adjust down if there were a population shift into the central district is wrong, so that there is some negative feedback to willingness to pay in the market in question, which would imply our results understate the price effect. In those cases, though, the density of the population at $q$ would likely spike due to the equilibrium condition of indifference among locations within a metropolitan area for similar households, and this likely stronger effect implies our results overstate the price effect.

We find generally small elasticities. For apartments in Manhattan, a demand elasticity for apartment space of -.4 would be moderate based on Hanushek and Quigley [7]. Under

\footnotetext{
${ }^{7}$ The corresponding normal, uniform and lognormal distributions have finite expectations.
} 
the normal distribution, this implies that the elasticity of interest $\eta_{q L}$ is not far from -0.1 , whatever the median threshold price $\theta$. With a constant elasticity, this implies that multiplying quantity by eight would reduce price by less than 15 percent. Multiplying quantity by eight in Manhattan would imply uniform heights of 100 stories, ${ }^{8}$ which the architects and planners we have talked with say would be devastating for amenity and generate high marginal construction cost. Substantially reducing price by increasing supply without major amenity effects thus appears infeasible in Manhattan.

The New York metropolitan area, with between five and ten percent of national population, is more plausibly a single housing market than Manhattan. For the metropolitan area, land (as opposed to square footage) is plausibly the scarce commodity. Gyourko and Voith [6] suggest that -.7 is a moderate demand elasticity for land. Table 1 implies that under the normal distribution, if the median American would be induced to move to metropolitan New York by a 70 percent reduction in price, halving land prices would require a 15-fold increase in available land. This follows from the listed elasticity of $-.26:\left(15^{-.26} \approx .5\right)$.

An alternative way to answer the question posed here would be to ask: what would a given elasticity of price with respect to land supply imply about the distribution of willingness to pay conditional on the land or square footage elasticity? We performed these calculations focusing on the central case of a land price elasticity of 1 . The implications on the distributions were unreasonable: e.g. in order for the land price elasticity to be 1 for the metro New York region (10\% of the national population), $87 \%$ of Americans would not be willing to move there unless price was zero (assuming normal distribution) and the median willingness to pay for land would have to be $0.468 \%$ of the current price under Pareto distribution. For Manhattan (.7\% of the population), the corresponding values were $99 \%$ mass at zero willingness to pay under normal distribution and median willingness to pay less than $0.0001 \%$ of the current price under Pareto distribution. ${ }^{9}$

It has become fashionable to discuss "two Americas": one consisting of of large coastal

\footnotetext{
${ }^{8}$ The 2005 New York City Housing and Vacancy Survey data show a mean height of at least 12.5 stories.

${ }^{9}$ These calculation are available upon request from the authors.
} 
metropolitan areas, where land use constraints are common, and the other consisting of largely unregulated exurban or rural interior regions. Land supply is generally thought to be quite elastic in the second region. If we bundle the 10 largest metropolitan areas (mostly coastal) into a single "island" region and the remainder of the country into another, then the assumption that outside prices do not change when island land supply changes may not be too far off. In Table 1, we find that with approximately $30 \%$ of US population, the price elasticity with respect to land supply in the meta coastal region would be approximately .5 if the median American would move into the coastal region if land prices fell by forty percent. In this case, prices would fall by approximately thirty percent if land supply doubled in the largest coastal cities. By contrast, if the median American would be induced to move into the largest regions with a 10 percent reduction in price, then the elasticity falls to .15 , and a doubling of supply would lead to a price decrease of just ten percent. Further, the assumption of a single market is suspect given easily available data. According to the 2000 US Census, residents of the Northeast were likelier to move to the South than to the West. Residents of the West were more likely to move to the South or Midwest than the Northeast. Recognizing that US prices may affect US population, we have presumably overstated the elasticity of price with respect to land supply.

We conclude that individual metropolitan areas are unlikely to increase "affordability" by encouraging more supply. Smaller metropolitan areas are likely to meet even less success than larger ones. If all regulated regions simultaneously lifted supply constraints, the price consequences might be somewhat larger. The price consequences of supply regulations depend on the distribution of threshold prices that induce mobility into different regions across the entire national population, and we recommend that empirical research focus on ways of identifying parameters of these distributions. 
Table 1: Elasticity of land price with respect to land quantity $\eta_{q L}$ under different distributions of willingness to pay $\theta$ and different land demand elasticities $\bar{\eta}_{l q}$

\section{Top panel: land demand elasticity $\bar{\eta}_{l q}=.4$}

Elasticity $\eta_{q L}$ under distribution...

\begin{tabular}{|c|c|c|c|c|c|c|}
\hline$\frac{\text { Market size }}{\text { National Population }}$ & Analog & $\frac{\text { Median valuation } \theta}{\text { price } q}$ & Pareto & Lognormal & Normal & Uniform \\
\hline $0.0020 \%$ & Hanover, NH & .1 & -0.2084 & -0.1231 & -0.0496 & 0.0000 \\
\hline $0.0020 \%$ & Hanover, NH & .3 & -0.1135 & -0.0659 & -0.0388 & -0.0000 \\
\hline $0.0020 \%$ & Hanover, NH & .6 & -0.0494 & -0.0284 & -0.0223 & -0.0000 \\
\hline $0.7 \%$ & Manhattan & .1 & -0.4437 & -0.2969 & -0.1251 & -0.0127 \\
\hline $0.7 \%$ & Manhattan & .3 & -0.2535 & -0.1646 & -0.0984 & -0.0099 \\
\hline $0.7 \%$ & Manhattan & .6 & -0.1142 & -0.0726 & -0.0572 & -0.0057 \\
\hline $10.0 \%$ & Metro New York & .1 & $-0.8613^{*}$ & -0.7264 & -0.3450 & -0.2064 \\
\hline $10.0 \%$ & Metro New York & .3 & -0.5758 & -0.4409 & -0.2768 & -0.1636 \\
\hline $10.0 \%$ & Metro New York & .6 & -0.2816 & -0.2082 & -0.1661 & -0.0962 \\
\hline $30.0 \%$ & Top 10 Metro & .1 & $-1.6081^{*}$ & -1.5065 & -0.9303 & -0.8766 \\
\hline $30.0 \%$ & Top 10 Metro & .3 & $-1.2132^{*}$ & -1.1056 & -0.7888 & -0.7394 \\
\hline $30.0 \%$ & Top 10 Metro & .6 & $-0.7143^{*}$ & -0.6293 & -0.5212 & -0.4839 \\
\hline \multicolumn{7}{|c|}{ Bottom panel: land demand elasticity $\bar{\eta}_{l q}=.7$} \\
\hline$\frac{\text { Market size }}{\text { National Population }}$ & Analog & $\frac{\text { Median valuation } \theta}{\text { price } q}$ & Pareto & Lognormal & Normal & Uniform \\
\hline $0.0020 \%$ & Hanover, NH & .1 & -0.1962 & -0.1188 & -0.0489 & 0.0000 \\
\hline $0.0020 \%$ & Hanover, NH & .3 & -0.1098 & -0.0647 & -0.0383 & 0.0000 \\
\hline $0.0020 \%$ & Hanover, NH & .6 & -0.0487 & -0.0282 & -0.0222 & 0.0000 \\
\hline $0.7 \%$ & Manhattan & .1 & -0.3916 & -0.2726 & -0.1206 & -0.0127 \\
\hline $0.7 \%$ & Manhattan & .3 & -0.2355 & -0.1568 & -0.0956 & -0.0099 \\
\hline $0.7 \%$ & Manhattan & .6 & -0.1104 & -0.0710 & -0.0562 & -0.0057 \\
\hline $10.0 \%$ & Metro New York & .1 & $-0.7148^{*}$ & -0.5964 & -0.3126 & -0.1944 \\
\hline $10.0 \%$ & Metro New York & .3 & -0.4910 & -0.3894 & -0.2556 & -0.1559 \\
\hline $10.0 \%$ & Metro New York & .6 & -0.2597 & -0.1960 & -0.1582 & -0.0935 \\
\hline $30.0 \%$ & Top 10 Metro & .1 & $-1.0848^{*}$ & -1.0376 & -0.7273 & -0.6941 \\
\hline $30.0 \%$ & Top 10 Metro & .3 & $-0.8895^{*}$ & -0.8302 & -0.6379 & -0.6052 \\
\hline $30.0 \%$ & Top 10 Metro & .6 & $-0.5882^{*}$ & -0.5293 & -0.4507 & -0.4225 \\
\hline
\end{tabular}




\section{References}

[1] R. J. Arnott and J. G. MacKinnon, Measuring the costs of height restrictions with a general equilibrium model, Regional Science and Urban Economics, 7(4):359-375, 1979.

[2] E. Glaeser, J. Gyourko, and R. Saks, Why is Manhattan so expensive?: Regulation and the rise in house prices, Journal of Law and Economics, 48(2):331-370, 2005.

[3] E. Glaeser, J. Gyourko, and R. Saks, Urban growth and housing supply, Journal of Economic Geography, 6:71-89, 2006.

[4] E. Glaeser, J. Gyourko, and R. Saks, Why have housing prices gone up, American American Economic Review Papers and Proceedings, forthcoming.

[5] J. Gyourko, C. J. Mayer, and T. Sinai. Superstar cities. Working Paper, Wharton, 2004.

[6] J. Gyourko and R. Voith. The price elasticity of demand for residential land. Real Estate Working Paper 329, Wharton, 2000.

[7] E. A. Hanushek and J. M. Quigley, What is the price elasticity of housing demand?, The Review of Economics and Statistics, 62:449-454, August 1980.

[8] W. C. Wheaton, Decentralized welfare: Will there be underprovision?, Journal of Urban Economics, 48(3):536-555, 2000. 